\title{
Ontology based Semantic e-Learning Model- A Review
}

\author{
Vaishali B. Shinde \\ Research Student \\ Dept. of CS \& IT, Dr. B.A.M. \\ University, Aurangabad
}

\author{
S. A. Khillare \\ Assistant Professor \\ SRTMU's New Model Degree \\ College, Hingoli
}

\author{
Mukta Dhopeshwarkar \\ Assistant Professor \\ Dept. of CS \& IT, Dr. B.A.M. \\ University, Aurangabad
}

\begin{abstract}
We focus on the role of ontologies in developing learning constraint- based tutors, a special class of intelligent tutoring system (ITS). Domain models for ITS are extremely difficult to develop, and therefore efforts devoted to automatic induction of the necessary knowledge are of critical importance for widening the real - world impact of ITS. Ontology formally represent knowledge as a set of concept within domain, and the relationship between pairs of concepts. It can be used to model a domain and support reasoning about concepts. This show ontology takes an important place in elearning system. Ontology is used to classify the things which are needed in e- learning system.
\end{abstract}

\section{General Terms \\ RDF, Ontology}

\section{Keywords}

ITS, Ontology, RDF

\section{INTRODUCTION}

e-Learning is not concerned with providing easy access to learning resources, anytime, anywhere, via a repository of learning resources, but is only concerned with supporting such features as personal definition of learning goals, and synchronous and a synchronous communication, and collaboration between learners and between learner and instructor. One of the hottest topic in recent year in the AI community, is Semantic Web. Semantic web is a mesh of information linked up in such a way as to be easily processable by machines, on global scale. The semantic Web approach develops language for expressing information in machine processable form. These, two lines defines the essence of the Semantic Web: its information in machine processable form. Semantic web defines as a global scale information mesh and also secondly defines, it as framework for expressing information. Both citations demonstrate the main principal of the Semantic Web. Information in web should be more machine processable and understandable. We use Web as a global database first of all for search. Today's search engines cannot search more precise that they do it now. May be the main reason is that the structure and size of current Web do not allow to make search more precise and efficient. The structure of documents and web itself, probably, can be changed in a better - machine processable way. [1]

\section{SEMANTIC WEB}

Semantic Web is not separate web but it is the extension to share current web which make possible information to share and reuse. Semantic Web Technology, provides such environment so that machines can talk with each other to fulfil the needs of the user by providing the right information. To accomplish this task, Semantic Web uses the number of techniques like Ontology, RDF, RDFs, XML and SPARQL.

\subsection{RDF}

RDF stands for Resource Description Framework and it is graph data model to organize data into the more meaningful way. RDF offers a simple graph model which consists of nodes (i.e. resources or literals) and binary relations (i.e. statements). It is a type of Semantic Network and is very similar to the Relational Model. The data things are organized with its attribute via links in the form of relation. [2]

RDF consist of triple. That's is, subject, predict and object. It is used to describe the various attributes of thing like name, DOB, city.

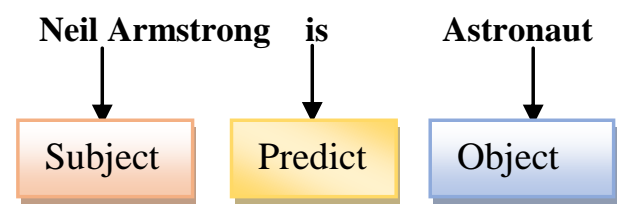

\subsection{Ontology}

A simple ontology for documents and their relationships to other components is depicted. Ontology is explicit of conceptualization. The class Document is used to annotate a resource which is a document. Documents describe some concepts. Ontology is helpful to create semantic web application to share and reuse information. [2] 


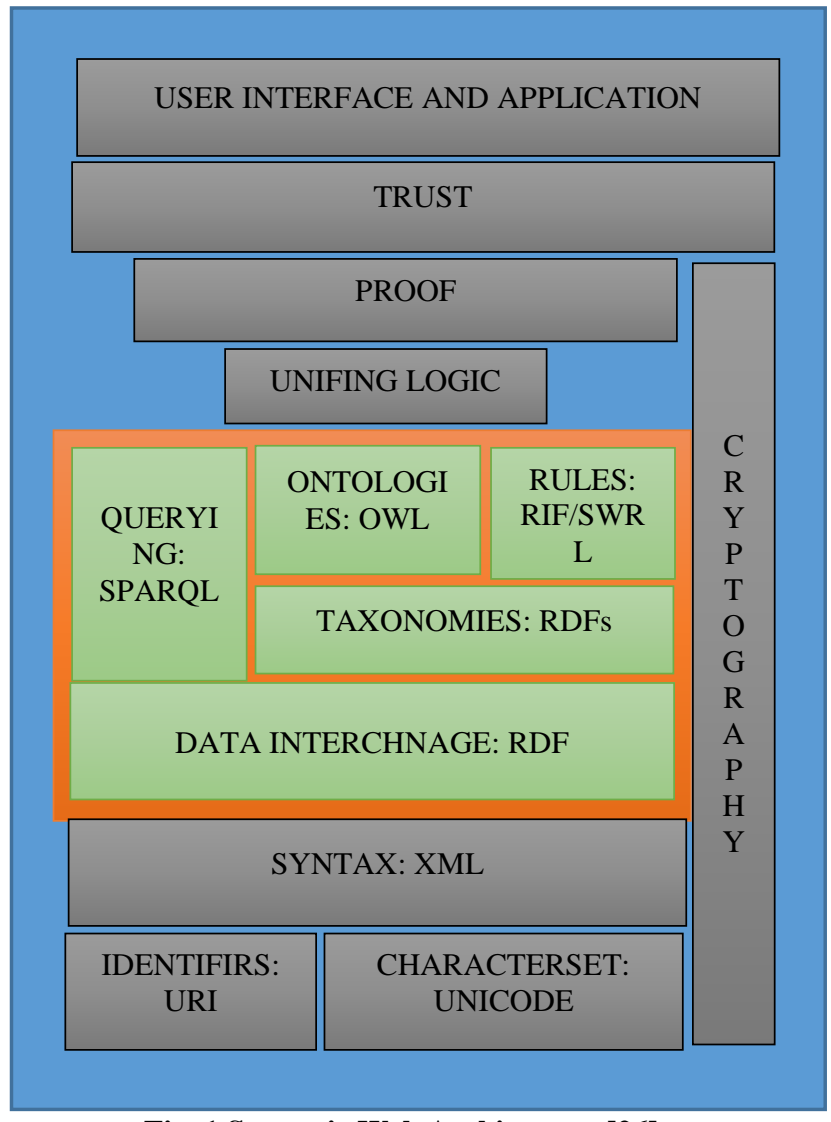

Fig. 1 Semantic Web Architecture [26]

\subsection{Ontology Types}

Ontologies are classified in various ways using criteria such as the degree of abstraction and field of application:

1. Upper ontology: concepts supporting development of an ontology, meta-ontology.

2. Domain ontology: concepts relevant to a particular topic or area of interest, for example, information technology or computer languages, or particular branches of science.

3. Interface ontology: concepts relevant to the juncture of two disciplines. 4. Process ontology: inputs, outputs, constraints, sequencing information, involved in business or engineering processes.

\section{LIMITATION OF CURRENT E- LEARNING ENVIRONMENTS E-} LEARNING (ELECTRONIC-LEARNING)

Is just learning using technologies like computer system, internet, and network [1]. Current e-learning environments is developed in computer programming languages. It works according to how it programmed well in advance. Sometimes it fails to supply learning resources according to the learner's needs, and produce irrelevant results which are not match to learner's query and interest. So that learner has to involve and spend time to categorize the web results which he/she actual require to learn [3]

\section{PROPOSED E-LEARNING ENVIRONMENTS USING SEMANTIC WEB TECHNOLOGY}

The proposed work will solve the problem of previous elearning environment and will be prove a better e -learning environment and will be prove a better e-learning environment which is based on semantic web technology.

In proposed work first identify the needs, interest, media to learn i.e. audio, video, pdf, and other, background, profile, knowledge level, search history of the e-learning before delivering the learning resource results to e-learning. The important thing is in this approach is that discovering, identifying, categorizing and presenting the relevant result to e- learner is performed by machine not the human. So, the learner can spend more time in learning activities and feel better learning environments. The mechanism is work on various techniques of Semantic Web Technology like Ontology, RDF, SPARQL and XML. [3]

\section{ONTOLOGY DEVELOPMENT FOR SEMANTIC E-LEARNING}

The core part of Semantic Web Technology is developing Ontology. The Ontology for document and their relationships to other component is depicted. The class document is used to annotate a resource which is document. Document describe some concepts. Use the class concept to annotate concepts. Concepts and Document are related through subject property. Concepts and documents have a certain role in their collaboration in certain document. These facts by instance of class and its property. [4]

Ontologies can be used in blended e-learning (on-line and face-to-face interaction) as a means to describe the formal organization of universities and training courses and to identify services. Must be on the ontology of e-learning, including a description of educational institutions (providers of course), and courses, and the people involved in the process of teaching and learning. Some suggestions are without the use of the footage that was created using WebOnto. [5]

Table 1. Difference between e-learning and tradition learning [6]

\begin{tabular}{|c|c|c|}
\hline Dimensions & E-Learning & Training Pull \\
\hline Delivery & $\begin{array}{c}\text { Pull - Student } \\
\text { determines agenda }\end{array}$ & $\begin{array}{c}\text { Push - Instructor } \\
\text { determines agenda } \\
\text { Non-linear }\end{array}$ \\
\hline Access & $\begin{array}{c}\text { Non-linear - } \\
\text { Allows direct } \\
\text { access to } \\
\text { knowledge in } \\
\text { whatever sequence } \\
\text { makes sense to the } \\
\text { situation at hand. }\end{array}$ & $\begin{array}{c}\text { Linear - Has defined } \\
\text { progression of } \\
\text { Knowledge. }\end{array}$ \\
\hline Responsiveness & $\begin{array}{l}\text { Reactionary - } \\
\text { Responds to } \\
\text { problem at hand }\end{array}$ & $\begin{array}{c}\text { Anticipatory - } \\
\text { Assumes to know the } \\
\text { problem }\end{array}$ \\
\hline
\end{tabular}




\begin{tabular}{|c|c|c|}
\hline Symmetry & $\begin{array}{l}\text { Symmetric - } \\
\text { Learning occurs as } \\
\text { an integrated } \\
\text { activity. }\end{array}$ & $\begin{array}{l}\text { Asymmetric - } \\
\text { Training occurs as a } \\
\text { separate Activity }\end{array}$ \\
\hline Personalization & $\begin{array}{l}\text { Personalized - } \\
\text { Content is } \\
\text { determined by the } \\
\text { individual users } \\
\text { needs and aims to } \\
\text { satisfy the needs of } \\
\text { every user. }\end{array}$ & $\begin{array}{l}\text { Mass produced-- } \\
\text { Content must satisfy } \\
\text { the Needs of many. }\end{array}$ \\
\hline Modality & $\begin{array}{l}\text { Continuous - } \\
\text { Learning runs in } \\
\text { the parallel to } \\
\text { business tasks and } \\
\text { never stops. }\end{array}$ & $\begin{array}{l}\text { Discrete - Training } \\
\text { takes place in } \\
\text { dedicated chunks with } \\
\text { defined starts and } \\
\text { stops. }\end{array}$ \\
\hline Adaptively & $\begin{array}{l}\text { Dynamic - Content } \\
\text { changes constantly } \\
\text { through user input, } \\
\text { experiences, new } \\
\text { practices, business } \\
\text { rules and heuristics }\end{array}$ & $\begin{array}{l}\text { Static - Content and } \\
\text { organization/taxonomy } \\
\text { Remains in their } \\
\text { originally authored } \\
\text { form without regard to } \\
\text { environmental } \\
\text { changes. }\end{array}$ \\
\hline Authority & $\begin{array}{l}\text { Distributed - } \\
\text { Content comes } \\
\text { from the } \\
\text { interaction of the } \\
\text { participants and the } \\
\text { educators. }\end{array}$ & $\begin{array}{l}\text { Centralized - Content } \\
\text { is selected from a } \\
\text { library of materials } \\
\text { developed by the } \\
\text { educator. }\end{array}$ \\
\hline
\end{tabular}

\section{LITERATURE WORK / REVIEW-}

When considering a learning model, one should look at the various aspects, elements and factors of such model. As we can see from the definitions above, a framework or a model, consists of a number of components (services), and has to serve (a) goal(s). The - put togetherl of those components to serve the intended goal(s) must be done in the right way, taking all elements and influential factors into consideration, in order for such model to be successful. Realizing the existence of various learning models - as seen above, each type has its own unique characteristics and requirements.

Burger and Rotherm et.al.(2001), focuses on special form of content in distributed system and computer networks. Specifically, it focuses on student requirements for learning material and animation application applets and on teacher's requirements. Extensible and consists of simulation and animated visualization. Focus on applets, more concepts are needed for integration into learning materials in multimedia. [7]

Anido Rifón et al (2001), having framework SimulNet for developing interactive and collaborative web-based applications. It is a layered architecture, consisting of commercial off-the- shelf services and standard Internet protocols, then services layer, components layer, and application layer. Many services and components. Tested with good evaluation. Suffers from performance problems when overloaded because it is $100 \%$ Java. Server 's multitasking model is based on Java threads where the OS considers that there is one large server process running one thread for each component.
Carman (2002), Five key ingredients of blended learning process. Live events, self-paced learning, collaboration, assessment, and performance There are many other ingredients, factors and elements not included. It looks at blended learning through those five ingredients only which makes it questionable when considering a complete blended learning model that takes most, if not all, ingredients; elements; factors and dimensions into account. [8]

Zhang et al (2004), by using the framework Virtual Mentor Based on constructivist learning theory. Consists of six principles: Multimedia-integration, Just-in- Time knowledge acquisition, Interactivity, Self- directivity, Flexibility, And Intelligence. Leaving all other dimensions/ factors aside, the model only takes one theory into consideration. Therefore, from pedagogical perspective, it does not take other theories into account like behavioral, And objectivist. This makes the model non-blended one from this perspective. [9]

Koohang \& Plessis et.al.(2004), Framework for e-learning usability properties. Five-category based on usability properties based on -looks great and works welll paradigm. It is based on usability attributes of usable product. This framework is for e- learning not blended learning as dealt with in the context of this research. It focuses on usability properties when constructing e-learning. [9]

Dewar \& Whittington et.al. (2004), by using framework VASE, For the development of blended learning. drawn on the work of others, especially Hocutt (2001). It is composed of Build a Vision, Check Assumptions, take a System View, and Expect Change. A number of questions for each theme to guide development of blended learning. It is not a blended learning model as such, rather it is a model to develop blended learning. Though it is a good attempt in this direction, it cannot be considered as blended learning model. [10]

Derntl \& Motschnig Pitrik et.al. (2004), used the framework BLESS for $r$ blended learning, layered approach. Five layers: blended learning courses, course scenarios, blended learning patterns, web templates, and learning platform. [11]

Tane, et al (2004), used the framework KAON i.e. Karlsruhe Ontology and Semantic Web Framework. It offers abstraction for ontologies and allows both the browsing and the querying of the resources available. [22]

Brusilovsky, et al (2005), used the framework ADAPT2 that is, Advanced Distributed Architecture for Personalized Teaching and Training. It employs a higher level mechanism for ontology based interoperability of self-contained ELearning framework. [14]

Kawamura, Nakatani, \& Sugahara et.al. (2005), Novel framework for asynchronous web-based training. Claims that it solved the problems of scalability and robustness that the existing WBT systems. Focuses only on one aspect; that is asynchronous WBT. It does not even take synchronous into account. Not much of a blend is there. [12]

Keil-Slawik, Hampel \& Eßmann et.al.(2005), Framework for pervasive eLearning. In distributed knowledge space, using executable learning objects. This is a very specific / focused framework on one type of eLearning, in a given environment. [13]

Abbas, et.al. (2006), Context-aware semantic E-learning approach It integrates Context-aware semantic e-learning approach to content provision, learning process. [17] 
Z. Abbas, M. Umer, M. Odeh et.al, this framework ALOCoM, Abstract Learning Object Content Model. It defines the different granularity levels that are present in current content models and their interrelationships. [15]

Gracia and Jorge et.al.(2006), they used Sharable Content Object Reference Model i.e. SCORM framework. It allows the instructors to set up a benchmark test for evaluating an ELearning platforms. [18]

Convertini, et al (2006), he used the framework OSEL that is Open Source E-Learning Taxonomy. It classifies the learning objects through an ontological definition and eliminates ambiguity. [23]

Snae and Brueckner et.al.(2007), used the framework for Ontology-Driven E-learning system. It enables the students to master the learning material and meet the learning goals of the course. [21]

Jovanovic, et.al.(2007), by using the framework LOCO i.e. Learning Object Context. It is a collection of metadata and promotes the integration and reuse of learning objects. [22]

Cernea, et.al. (2008), SOAF framework model that is Semantics of Learning Objects based on folksonomies he used for making e-learning model. It classifies the learning objects in a repository by combining the emergent semantics with the users. [24]

Qwaider et.al.(2012) he made Semantic Web portal by the name, Semantic Web Portal concept. It is used in blended Elearning to describe the formal organization of universities and training courses to identify services. [ ]

Garrido and Morales et.al. (2014), made Content Personalization in e-learning. It used for extracts metadata information from the E-Learning contents and form a reusable learning objects. [25]

\section{CONCLUSION}

Ontology formally represents knowledge as a set of concepts and the relationships between pairs of concepts. It can be used to model a domain and support reasoning about concepts. This paper showed some basic and important concept of Ontology in E-Learning Systems. I hope that readers definitely understand the importance of Ontology in semantic web. Ontology is used to classify the things which are needed in ELearning Systems. This work will be used for students and researcher those who are more interested in data mining concepts. And I have used Very simple words to understand the concept of Ontology in E-Learning Systems.

\section{REFERENCES}

[1] w. Q, "Semantic Web Technologies Applied to ELearning System Qwaider, W Q," International Journal of Computer Applications, vol. 47, no. 10, pp. 12-17, 2012.

[2] J. R. G. Pulido, "Ontology languages for the semantic web: A never completely updated review," KnowledgeBased Systems, vol. 19, no. 7, pp. 489-497, 2006.

[3] O. A. S. Ghassan, "Development of a model for blended learning in traditional universities in Palestine / Ghassan O A Shahin," no. August, 2012

[4] T. M. Mahmoud, "A Framework for An E-Learning System Based on Semantic Web," International Journal on Computer Science and Engineering (IJCSE), vol. 5, no. 08 , pp. 698-710, 2013
[5] Berners-Lee, "The Semantic Web," Scientific American, vol. 284 , no. 5 , pp. $34-43,2001$

[6] Domingue, J. (1998). Tadzebao and WebOnto Discussing, Browsing, and Editing Ontologies on the Web. Paper presented at the 11th Knowledge Acquisition for Knowledge-Based Systems Workshop, 18-23 April, Banff, Alberta, Canada.

[7] Burger, C., \& Rothermel, K. (2001). A framework to support teaching in distributed systems. Journal on Educational Resources in Computing (JERIC), 1(1es), Article 3.

[8] Carman, J. M. (2002). Blended learning design: Five key ingredients. Retrieved from http://www.knowledgenet.com/pdf/Blended\%20Learning \%20Design_1028.PDF also available at http://mizanis.net/edu3105/artikel/BlendedLearningDesign.pdf

[9] Koohang, A., \& Du Plessis, J. (2004). Architecting usability properties in the e-learning instructional design process. International Journal on E-Learning, 3(3), 3844.

[10] Dewar, T., and Whitting, D. (2004) Blended learning research report. Calliope Learning,2(1),1-12.

[11] Derntl, M., \& Motschnig-Pitrik, R. (2004)-b. Patterns for blended, Person-Centered learning: strategy, concepts, experiences, and evaluation. Paper presented at the ACM Symposium on Applied Computing, Nicosia, Cyprus, March 14-17, 2004

[12] Kawamura, T., Nakatani, R., \& Sugahara, K. (2005). P2P E-learning System and its Squeak-based User Interface. Paper presented at the Third International Conference on Creating, Connecting and Collaborating through Computing (C5‘05)

[13] Keil-Slawik, R., Hampel, T., \& Eßmann, B. (2005). Reconceptualizing learning environments: a framework for pervasive e-learning. Paper presented at The 3rd International Conference on Pervasive Computing and Communications Workshops (PerCom 2005 Workshops), Kauai Island, Hawaii, 08- 12 March 2005, ISBN: 0- 7695-2300-5.

[14] W. Huang, D. Webster, D. Wood, and T. Ishaya, "An intelligent semantic e-learning framework using context-aware Semantic Web technologies," British Journal of Educational Technology, vol. 37, pp. 351-373, 2006.

[15] Z. Abbas, M. Umer, M. Odeh, R. McClatchey, A. Ali, and A. Farooq, "A semantic grid-based e-learning framework (SELF)," in Cluster Computing and the Grid, 2005. CCGrid 2005.

[16] K. Verbert and E. Duval, "ALOCOM: a generic content model for learning objects," International Journal on Digital Libraries, vol. 9, pp. 41-63, 2008.

[17] Snae and M. Brüeckner, "Ontology-driven e-learning system based on roles and activities for Thai learning environment," Interdisciplinary Journal of E-Learning and Learning Objects, vol. 3, pp. 1-17, 2007.

[18] B. García and A. H. Jorge, "Evaluating e-learning platforms through SCORM specifications," in IADIS 
Virtual Multi Conference on Computer Science and Information Systems (MCCSIS 2006), IADIS, 2006.

[19] J. Jovanović, D. Gašević, C. Knight, and G. Richards, "Ontologies for effective use of context in e-learning settings," Educational Technology \& Society, vol. 10, pp. $47-59,2007$.

[20] P. Brusilovsky, S. Sosnovsky, and M. Yudelson, "Ontology-based framework for user model interoperability in distributed learning environments," in World Conference on E-Learning in Corporate, Government, Healthcare, and Higher Education, 2005, pp. 28512855.

[21] P. Markellou, I. Mousourouli, S. Spiros, and A. Tsakalidis, "Using semantic web mining technologies for personalized e-learning experiences," Proceedings of the web-based education, pp. 461-826, 2005.

[22] J. Tane, C. Schmitz, and G. Stumme, "Semantic resource management for the web: an e-learning application," in Proceedings of the 13th international World Wide Web conference on Alternate track papers \& posters, 2004, pp. 1-10.

[23] V. Convertini, D. Albanese, A. Marengo, V. Marengo, and M. Scalera, "The OSEL taxonomy for the classification of learning objects," Interdisciplinary Journal of E-Learning and Learning Objects, vol. 2, pp. 125-138, 2006

[24] D. Cernea, E. Del Moral, and J. Gayo, "SOAF: Semantic indexing system based on collaborative tagging," Interdisciplinary Journal of E-Learning and Learning Objects, vol. 4, pp. 137-149, 2008.

[25] Garrido and L. Morales, "E-Learning and Intelligent Planning: Improving Content Personalization," IEEE REVISTA IBEROAMERICANA DE TECNOLOGIAS DEL APRENDIZAJE, vol. 9, 2

[26] G. Abraham. (2013) The Semantic Web Architecture. [Online].

Available: semanticweb-architecture.html 